\title{
NOTES AND QUERIES.
}

The Erb Medal was awarded to Dr. Robert Bárány, of Vienna, at the recent meeting of German neurologists in Breslau.

A department for the treatment of Diseases of the Ear, Nose and Throat has been established at the Torbay Hospital, Torquay. Mr. T. G. Fenton has been appointed surgeon-in-charge.

\section{Royal Devon and Exiter Hospital.}

It has been decided to initiate a Throat, Nose and Ear Department in this hospital, and the necessary accommodation is being provided in the out-patient department.

\section{The Semon Lecture, 1914.}

Prof. Killian, of Berlin, will deliver the Semon Lecture at the Barnes Hall, Royal Society of Medicine, 1, Wimpole Street, London, W., on Thursday, May 28 next, at 5 p.m. Sir Felix Semon will occupy the Chair. Subject: "Suspension Laryngoscopy and its Practical Use."

The May meeting of the Section of Laryngology of the Royal Society of Medicine will be held on Wednesday, May 27, at 4 p.m.

\section{The Combined Dinner of the Sections of Otology and Laryngology of} THE Royat Society of Mrdicine.

This dinner will be held on May 28 (the evening of the Semon Lecture) at the Trocadero Restaurant, Piccadilly Circus, London, W., at 7.30 p.m., Dr. D. R. Paterson (President of the Section of Laryngology) in the Chair.

Members who wish to attend are requested to send in their names as early as possible to one of the secretaries-Mr. G. J. Jenkins, 48, Wimpole Street, London, W., or Dr. E. A. Peters, 52, Wimpole Street, London, W.

\section{BOOKS RECEIYED.}

Bulletin et Mémoires de la Société de Laryngologie, d'Otologie et de Rhinologie de Paris. Vigot Frères, Editeurs, 23, Place de l'Ecolede-Médecine, Paris, 1914.

Carbon Dioxide Snow : Its Therapeutic Uses. (Methods of Collection and Application.) By J.Hall-Edwards. London : Simpkin, Marshall, Hamilton, Kent \& Co., Ltd., 1913.

Anæesthetics : their Uses and Administration. By Dudley W. Buxton, M.D. Fifth Edition. Enlarged. Pp. xiv +477 . Price 10s. $6 d$. net. London : H. K. Lewis, 1914.

Traitement des Stenoses Aiguës du Largnx. Par le Dr. Guillermo Zorraquin. Paris: Vigot Frères. Prix 2 francs.

Jahresbericht über die Fortschritte der Laryngologie, Rhinologie und ihrer Grenzgebiete. Herausgegeben von Dr. F. Blumenfeld, Wiesbaden. Preis 6 marks. 


\section{CENTRAL LONDON THROAT AND-EAR HOSPITAL GRAY'S INN ROAD (Near King's cross Stations).}

The work carried on at this Hospital comprises :

\section{The Daily Out-Patient Glinic.}

The Medical Officers attend as follows :

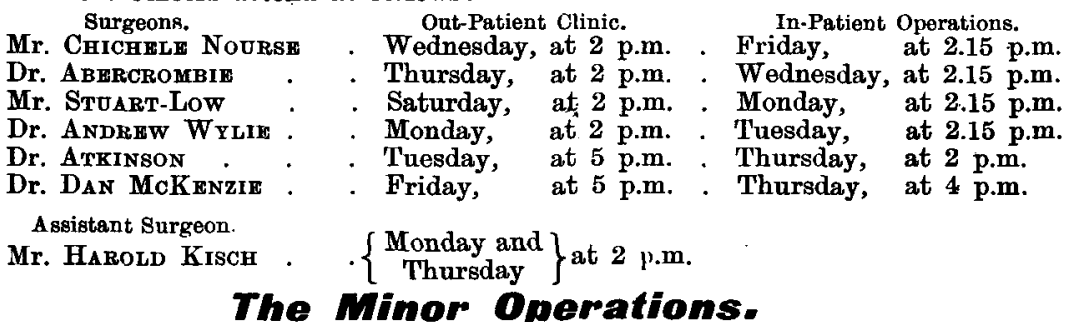

The Minor Operations.

These are performed at 9 a.m. on Monday, Tuesday, Wednesday, Thursday, Friday.

3.

The Im-Patient Department. Major Operations.

These take place at 2 o'clock on Monday, Tuesday, Wednesday, Thursday, Friday.

The list of operations is to be seen on the notice board in the Out-patient Consulting Room

\section{Leotures and Demonstrations.}

Courses of Practical Instruction are given throughout the year by Members of the Staff, on Tuesdays and Fridays, at 3 p.m. punctually.

The Courses consist of two classes twice a week devoted to Anatomy, Pathology, Diagnosis and Treatment of the special diseases dealt with at the Hospital. They may be joined at any time.

A Surgical Anatomy and Operative Surgery Class is held when desired. 'The teaching is practical and demonstrative, and is illustrated by diagrams, models, specimens and instruments.

\section{5.}

\section{The Pathological Laboratory}

Is at all times available to students. Dr. Wyatt Wingrave, Pathologist to the Hospital, is in attendance daily at 3 p.m.

\section{Glinical Assistants}

Are appointed from among those gentlemen who have enrolled themselves for attendance on the practice of the hospital.

Further particulars may be had on application to the Dean.

\section{Fees.}

$\begin{array}{ccccc}\text { Course of Practical Instruction } & \ldots & \ldots & \ldots & 1 \text { guinea. } \\ \text { Operative Surgery Class" } & \text { with atterdance at Clinics } & \mathbf{2} \text { guineas. }\end{array}$

For attendance on the practice of the Hospital (Clinical Assistants)-

$\begin{array}{llc}\text { Three months } & \ldots & 5 \\ \text { Six } & \ldots & 8 \text { guineas. } \\ \text { Perpetual ticket } & \cdots & 10,\end{array}$

Clinical Assistants are admitted to the Practical Course Free.

WYATT WINGRAYE, M.D., Dean.
RICHARD KERSHAW, Secretary Superintendent. 


\section{DAN MCKENZIE'S}
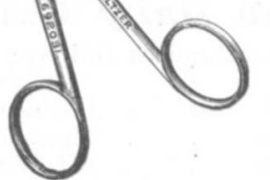

B

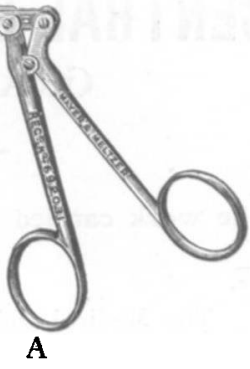

\section{Improved DIRECT ACTION NIBBLING FORCEPS,}

With improved joint, which obviates all " kick" when closing the forceps. Absolutely steady in use. ("Emandem" Registered Design.)

$\begin{array}{llllrrr}\text { A. Straight pattern } \ldots & \ldots & \ldots & \ldots & 81 & 17 & 6 \\ \text { B. Rectangular for anterior commissure } & \ldots & 2 & 0 & 0\end{array}$

\section{Improved Aseptic Guillotine. \\ Designed by HUGH JONES, M.R.C.S., L.R.C.P. \\ "Registered."}

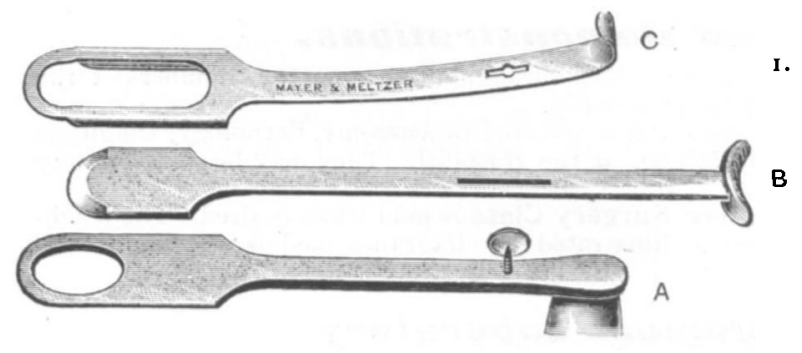

Advantages.

I. The instrument consists of three parts only-

A. The bed or lower plate to which the handle and turn button are fixed and of which they form part.

B. The blade.

C. The spring upper sheath.

There are no screws or other small fittings which are liable to be lost.

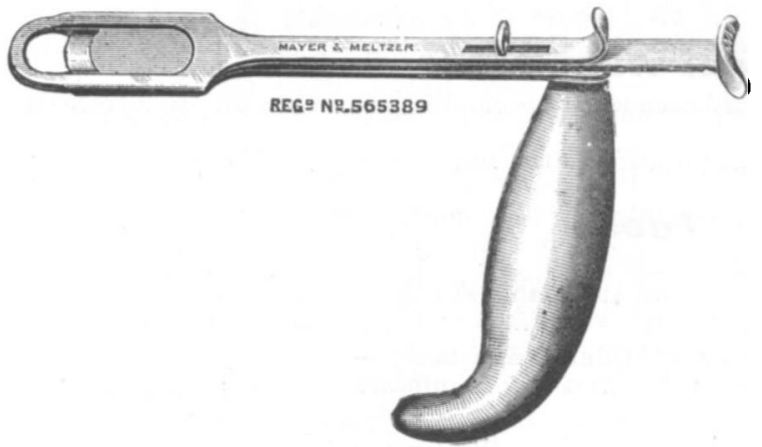

2. The handle is a fixture and cannot turn or become loose at a critical moment.

3. The upper sheath being removable, all parts of the instrument are accessible for cleaning.

4. The spring sheath exerts pressure on the blade at just the right point to ensure its accurately fitting the bed plate and so cutting efficiently.

5. The shape of the handle and the angle at which it is set, combined with the diminished length of the instrument, give greatly increased leverage, making it possible to entirely enucleate a tonsil if the

Made in 3 sizes, each 25/.. proper size guillotine is selected.

\section{MAYER \& MELTZER, 71, GT. PORTLAND STREET, LONDON.}

Branches: MELBOURNE; CAPETOWN; JOHANNESBURG. 


\section{MAYER

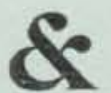 \\ $M$ \\ ELTZER,}

Surgical Instrument Makers.

1863 ESTABLISHED 50 YEARS

\section{Instrument to Facilitate Per=Oral Bronchoscopy.}

Devised by Writuam HrLl, M.D., and shown at the May Meeting of the Laryngological Section of the Royal Society of Medicine.

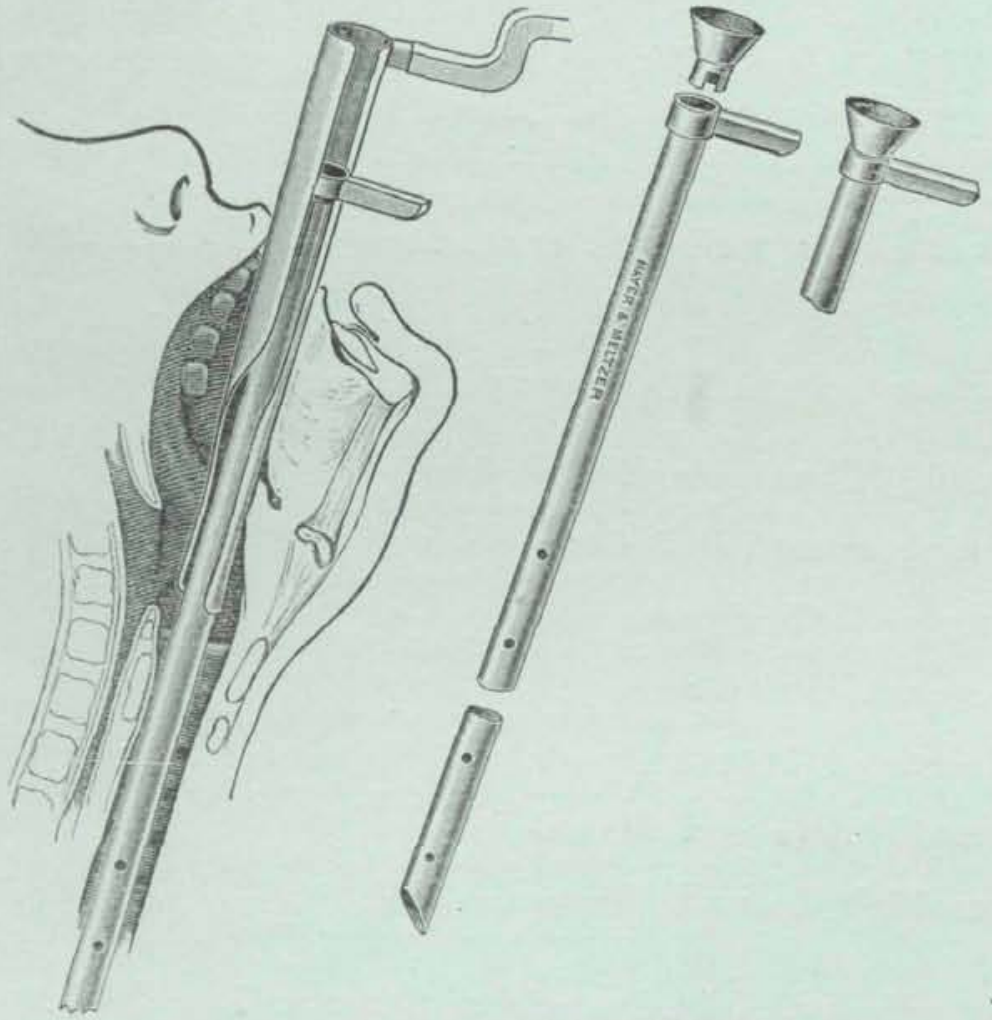

The lateral slot not only permits of binocular vision and easy instrumentation when operating on the larynx, but it also facilitates the rapid passage of a tracheoscope or bronchoscope in cases where (I) there is dyspncea from spasm, etc., during operations on the larynx, more especially in children; (2) for per-oral tracheobronchoscopic explorations where there is difficulty or delay in finding the contracted laryngeal vestibule, more especially when working with a narrow bronchoscope alone in children; (3) to relieve at once, without resorting to tracheotomy, the temporary spasmodic dyspnoa which sometimes supervenes on administering an anzesthetic in cases of laryngeal and tracheal obstruction.

Full particulars of Dr. William Hill's CEsophagoscopic Instrument and of the Gastroscope will be found in

\section{Our New :: Laryngology-Rhinology - Otology
Catalogue of}

containing upwards of 1700 illustrations, just published. If you have not received a copy it is due to an oversight, which will be promptly remedied on receipt of a postcard.

\section{MAYER \& MELTZER, 71, GREAT PORTLAND ST., LONDON.}

Branches: MELBOURNE; CAPETOWN; JOHANNESBURG. : 


\section{The "Allenburys" \\ (мевгеттro) Throat Pastilles}

Efficient

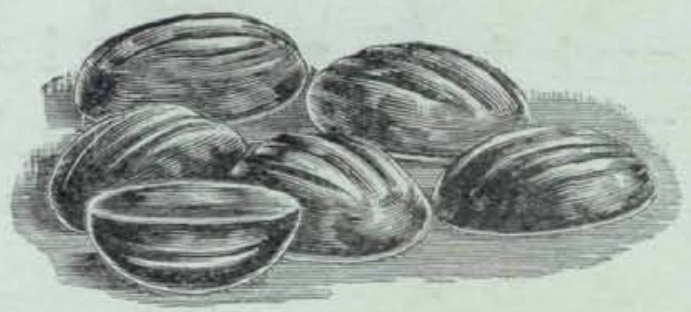

Palatable

The basis of the "Allenburys" Throat Pastilles is a special pâte de jujube. The pastilles are demulcent, soluble and palatable, and contain accurate amounts of pure active drugs. They dissolve slowly and uniformly, so ensuring the thorough suffusion of the mucous membrane, and the prolonged continuous direct effect of the active ingredients.

The following pastilles are largely used, and have been found from long practical experience to be very efficacious.

No. 9. Menthol, Cocaine and Red Gum

Menthol, gr. 1/20th; Cocaine, kr. 1/20th : Red Gum, Br. 2

No. 23. Eucalyptus and Red Gum

No. 28. Compound Guaiacum

Guaiacum, Er. 1; Chlorate of Potash. Br. 2: Red Gum, Br. $\frac{1}{4}$

No. 29. Compound Rhatany

No. 38. Chlorate of Potash, Borax and Cocaine

No. 75. Formaldehyde and Menthol

No. 77. Formaldehyde and Cinnamon Oil

Formaldehyde, min. 1; Ol. Cinnamon, min. th

1/- box of any variety, with detailed list, free to Medical Men in Great Britain.

IMPORTANT.-To ensure the supply of these active and reliable medicinal products, medical men should designate the

"ALLENBURYS" Pastilles in their prescriptions.

Allen \& Hanburys Itd. London

NIAGARA FALLS, N.Y.

TORONTO.

BUENOS AIRES.

DURBAN.

SYDNEY. 